\title{
Even Vertex Graceful of Path, Circuit, Star, Wheel, some Extension-friendship Graphs and Helm Graph
}

\author{
A. Solairaju ${ }^{1}$, P. Muruganantham ${ }^{2}$ \\ ${ }^{1}$ Associate Professor of Mathematics, Jamal Mohamed College, Trichy, India. \\ ${ }^{2} \mathrm{Head}$, Dept of Mathematics, Kurinji College of Arts and Science, Trichy, India.
}

\begin{abstract}
Even vertex gracefulness of path, circuit, star and wheel are obtained. Also even vertex gracefulness of the connected graphs $\mathrm{C}_{\mathrm{n}} \nabla \mathrm{F}\left(2 \mathrm{nC}_{3}\right), \mathrm{C}_{\mathrm{n}} \nabla \mathrm{F}\left(3 \mathrm{nC}_{3}\right)$ and $\mathrm{C}(4, \mathrm{n})$ are got.
\end{abstract}

\section{INTRODUCTION}

A.Solairaju, and A.Sasikala [2008] got gracefulness of a spanning tree of the graph of product of $\mathrm{P}_{\mathrm{m}}$ and $\mathrm{C}_{\mathrm{n}}$, A.Solairaju and K.Chitra [2009] obtained edge-odd graceful labeling of some graphs related to paths. A.Solairaju, and C. Vimala [2008] also got the gracefulness of a spanning tree of the graph of Cartesian product of $S_{m}$ and $S_{n}$.

A.Solairaju and P.Muruganantham [2009] proved that ladder $\mathrm{P}_{2} \times \mathrm{P}_{\mathrm{n}}$ is even-edge graceful (even vertex graceful). They found [2010] the connected graphs $\mathrm{P}_{\mathrm{n}} \circ \mathrm{nC}_{3}$ and $\mathrm{P}_{\mathrm{n}} \mathrm{onC} \mathrm{n}_{7}$ are both even vertex graceful, where $\mathrm{n}$ is any positive integer. They also obtained [2010] that the connected graph $\mathrm{P}_{\mathrm{n}} \Delta \mathrm{nC}_{4}$ is even vertex graceful, where $\mathrm{n}$ is any even positive integer.

\section{Section I: Preliminaries}

Definition 1.1: Let $G=(V, E)$ be a simple graph with $p$ vertices and $q$ edges.

A map $\mathrm{f}: \mathrm{V}(\mathrm{G}) \rightarrow\{0,1,2, \ldots, \mathrm{q}\}$ is called a graceful labeling if

(i) $\mathrm{f}$ is one - to - one

(ii) The edges receive all the labels (numbers) from 1 to $\mathrm{q}$ where the label of an edge is the absolute value of the difference between the vertex labels at its ends.

A graph having a graceful labeling is called a graceful graph.

Definition 1.2: A graph is if there exists an injective map $\mathrm{f}: \mathrm{E}$ $(\mathrm{G}) \rightarrow\{1,2, \ldots, 2 \mathrm{q}\}$ so that the induced map $\mathrm{f}^{+}: \mathrm{V}(\mathrm{G}) \rightarrow\{0,2$, $4, \ldots, 2 \mathrm{k}-2\}$ defined by $\mathrm{f}^{+}(\mathrm{x})=\sum \mathrm{f}(\mathrm{xy})(\bmod 2 \mathrm{k})$ where $\mathrm{k}=\max \{$ $\mathrm{p}, \mathrm{q}\}$ makes all distinct.

Definition 1.3: $C_{n}$ is a circuit with $n$ vertices. $S_{n}$ is a star with $n$ vertices. $\mathrm{W}_{\mathrm{n}}$ is a wheel with $\mathrm{n}$ vertices.

\section{Section II: Even vertex graceful of standard graphs}

The following result is first started.

Theorem 2.1: A path with $n$ vertices is even vertex graceful.

Proof: A path $P_{n}$ is a connected graph with $n$ vertices. It has (n-1) edges as follows:

$P_{n}$

Some arbitrary labeling of edges of the path $\mathrm{Pn}$ is given below:

\begin{tabular}{|c|c|c|c|c|c|c|c|}
\hline$e_{1}$ & $e_{2}$ & $e_{3}$ & $e_{4}$ & $e_{5}$ & $e_{6}$ & $e$ & $e_{1}$ \\
\hline
\end{tabular}

Define $\mathrm{f}: \mathrm{E}\left(\mathrm{P}_{\mathrm{n}}\right) \rightarrow\{1,2, \ldots,(\mathrm{n}-1)\}$ by $\mathrm{f}\left(\mathrm{e}_{\mathrm{i}}\right)=2 \mathrm{i}$, i varies from 1 to (n-1).

Then the induced map $\mathrm{f}^{+}(\mathrm{u})=\sum \mathrm{f}(\mathrm{uv}) \quad(\bmod 2 \mathrm{q})$ where the sum runs over all edges uv through $v$. Now, $f$ and $f^{+}$both satisfy even vertex graceful labeling. The path $P_{n}$ with $n$ vertices is even vertex graceful.

Example 2.1: The path $P_{13}$ is even vertex graceful.

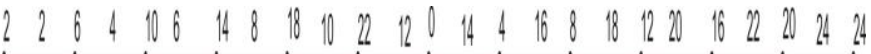

Theorem 2.2: A circuit $C_{n}$ with $n$ vertices is even vertex graceful. Proof: Some arbitrary labeling of edges of $C_{n}$ is as follows:

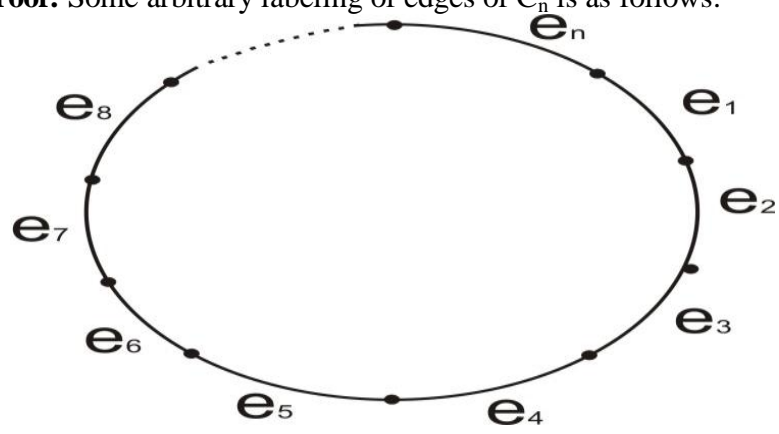

Define $f: E\left(C_{n}\right) \rightarrow\{1,2, \ldots, n\}$ by $f\left(e_{i}\right)=2 i$, i varies from 1 to $n$. Then the induced map $\mathrm{f}^{+}(\mathrm{u})=\sum \mathrm{f}(\mathrm{uv}) \quad(\bmod 2 \mathrm{q})$ where the sum runs over all edges uv through $v$. Now, $f$ and $f^{+}$both satisfy even vertex graceful labeling. The path $C_{n}$ with $n$ vertices is even vertex graceful.

Example 2.2: The path $C_{11}$ is even vertex graceful.

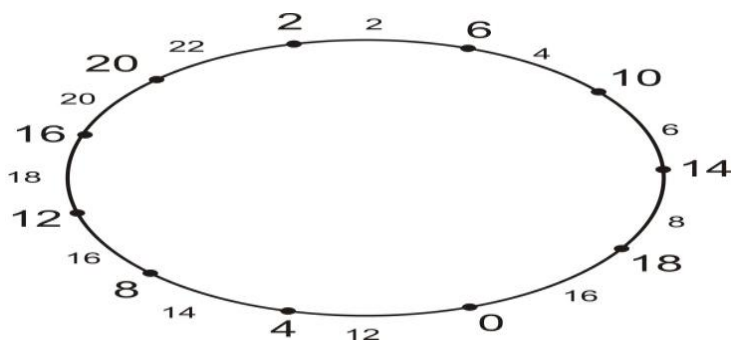

Theorem 2.3: A star with $n$ vertices $\left(S_{n}\right)$ is even vertex graceful. Proof: Some arbitrary labeling of edges of $S_{n}$ is as follows:

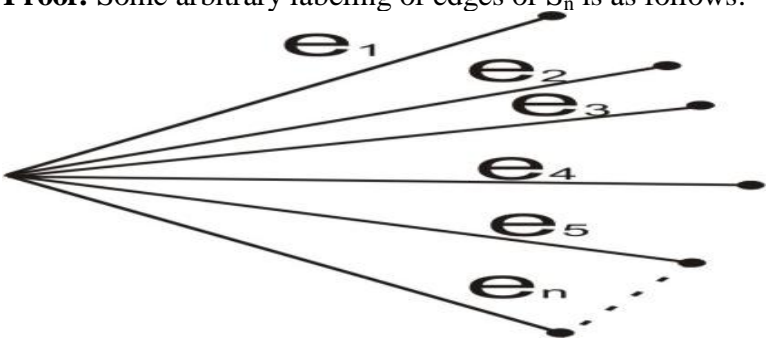


Define $f: E\left(S_{n}\right) \rightarrow\{1,2, \ldots, n\}$ by $f\left(e_{i}\right)=2 i$, i varies from 1 to $n$. Then the induced map $\mathrm{f}^{+}(\mathrm{u})=\sum \mathrm{f}(\mathrm{uv}) \quad(\bmod 2 \mathrm{q})$ where the sum runs over all edges uv through $v$. Now, $f$ and $\mathrm{f}^{+}$both satisfy even vertex graceful labeling. The path $S_{n}$ with $n$ vertices is even vertex graceful.

Example 2.3: The star $\mathrm{S}_{6}$ is even vertex graceful.

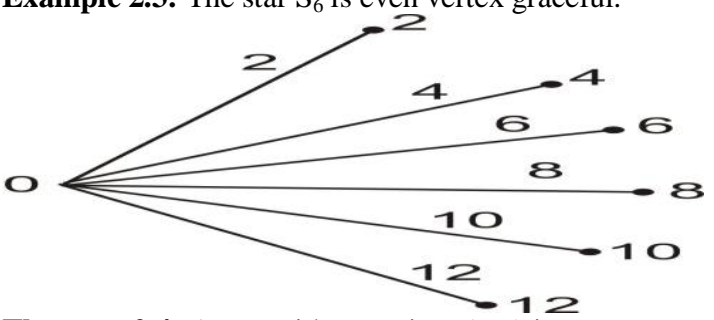

Theorem 2.4: A star with $n$ vertices $\left(\mathrm{W}_{\mathrm{n}}\right)$ is even vertex graceful. Proof: Some arbitrary labeling of edges of $\mathrm{W}_{\mathrm{n}}$ is as follows:

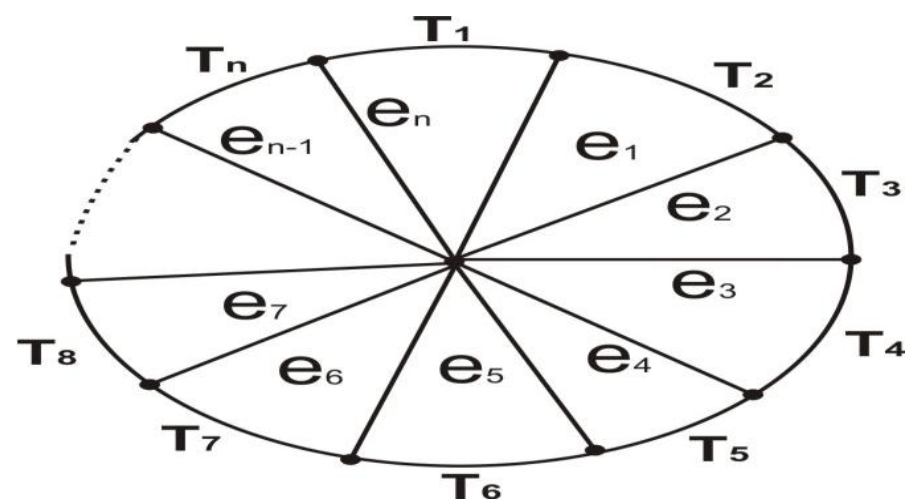

Define $f: E\left(C_{n}\right) \rightarrow\{1,2, \ldots, n\}$ by $f\left(T_{j}\right)=(2 j-1), i$ varies from 1 to $n$;

$n$ is even : $f\left(e_{i}\right)=2 q-2(i-1)$, i varies from 1 to $n$.

$\mathrm{n}$ is odd and $\mathrm{n} \equiv 3(\bmod 4) ; \mathrm{f}\left(\mathrm{e}_{\mathrm{n}-\mathrm{i}}\right)=2 \mathrm{i}+2, \mathrm{i}$ varies from 1 to $(\mathrm{n}-$ $1) ; \mathrm{f}\left(\mathrm{e}_{\mathrm{n}}\right)=\mathrm{f}\left(\mathrm{e}_{1}\right)+2$.

$\mathrm{n}$ is odd and $\mathrm{n} \equiv 1(\bmod 4) ; \mathrm{f}\left(\mathrm{e}_{\mathrm{n}-\mathrm{i}}\right)=2 \mathrm{i}$, i varies from 1 to $(\mathrm{n}-1)$; $\mathrm{f}\left(\mathrm{e}_{\mathrm{n}}\right)=\mathrm{f}\left(\mathrm{e}_{1}\right)+2$. Then the induced map $\mathrm{f}^{+}(\mathrm{u})=\sum \mathrm{f}(\mathrm{uv}) \quad(\bmod$ $2 q)$ where the sum runs over all edges uv through v. So $f$ and $\mathrm{f}^{+}$both satisfy even vertex graceful labeling. The path $S_{n}$ with $\mathrm{n}$ vertices is even vertex graceful.

Example 2.4: The path $\mathrm{W}_{14}$ is even vertex graceful.

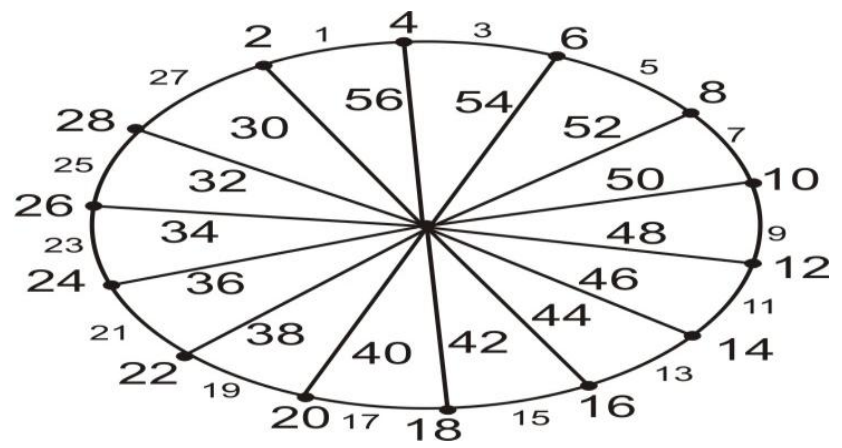

\section{Section 3 - Even vertex graceful of extension- friendship graph}

Definition 3.1: A fan graph or an extension-friendship graph $C_{n} \nabla$ $\mathrm{F}\left(2 \mathrm{nC}_{3}\right)$ is defined as the following connected graph such that every vertex of $C_{n}$ is merged with one copy of $2 C_{3}$.

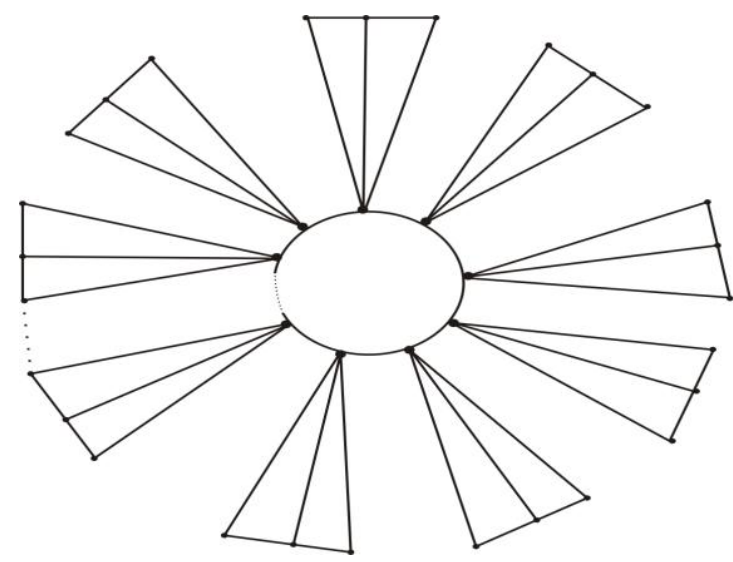

Theorem 3.1: The connected graph $C_{n} \nabla F\left(2 n C_{3}\right)$ is even vertex graceful.

Proof: The graph $\mathrm{C}_{\mathrm{n}} \nabla \mathrm{F}\left(2 \mathrm{nC}_{3}\right)$ is chosen with some arbitrary labeling of edges as in definition (1.5).

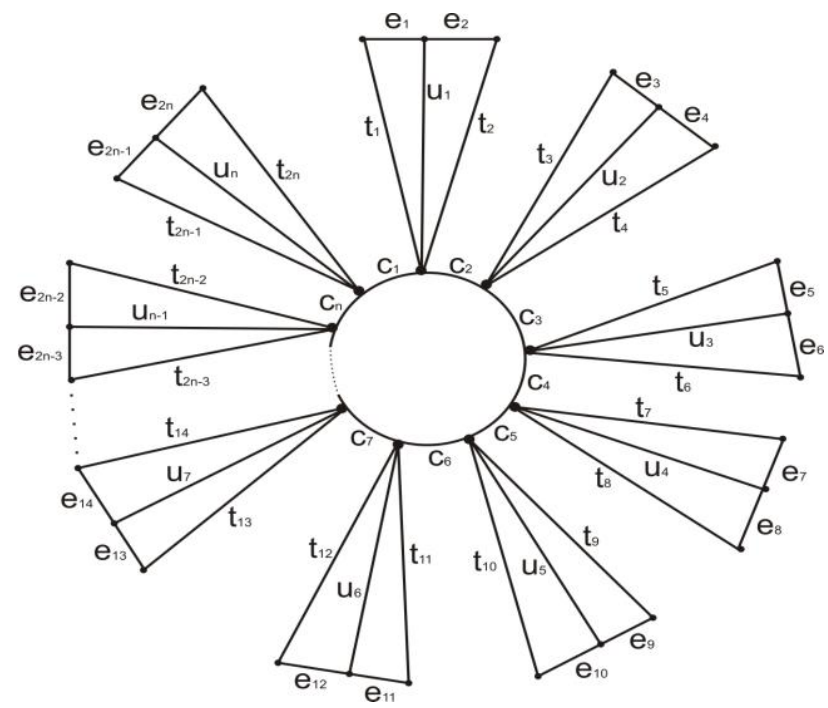

Define a map $\mathrm{f}: \mathrm{E}\left[\mathrm{C}_{\mathrm{n}} \nabla \mathrm{F}\left(2 \mathrm{nC}_{3}\right)\right] \rightarrow\{0,1,2, \ldots, 2 \mathrm{q}\}$ by

$$
\begin{array}{lr}
\mathrm{f}\left(\mathrm{e}_{\mathrm{i}}\right)=2 \mathrm{i}-1, & \mathrm{i}=1,2, \ldots 2 \mathrm{n} \\
\mathrm{f}\left(\mathrm{t}_{\mathrm{i}}\right)=(2 \mathrm{i})+\mathrm{f}\left(\mathrm{e}_{2 \mathrm{n}}\right) & \mathrm{i}=1,2, \ldots 2 \mathrm{n} \\
\mathrm{f}\left(\mathrm{u}_{1}\right)=2 \mathrm{q} & \mathrm{i}=2, \ldots \mathrm{n} \\
\mathrm{f}\left(\mathrm{u}_{\mathrm{i}}\right)=2 \mathrm{q}-4 \mathrm{i}+4 & \\
\mathrm{f}\left(\mathrm{c}_{1}\right)=\mathrm{f}\left(\mathrm{u}_{\mathrm{n}}\right)-2 & \\
\mathrm{f}\left(\mathrm{c}_{2}\right)=\mathrm{f}\left(\mathrm{c}_{1}\right)-6 & \\
\mathrm{f}\left(\mathrm{c}_{\mathrm{i}}\right)=\mathrm{f}\left(\mathrm{c}_{2}\right)-4(\mathrm{i}-2) & \mathrm{i}=3,4, \ldots \mathrm{n}
\end{array}
$$

Then the induced map $\mathrm{f}^{+}(\mathrm{u})=\sum \mathrm{f}(\mathrm{uv}) \quad(\bmod 2 \mathrm{q})$ where the sum runs over all edges uv through $\mathrm{v}$. Now, $\mathrm{f}$ and $\mathrm{f}^{+}$both satisfy even vertex graceful labeling as well as edge-odd graceful labeling. Thus the connected graph $\mathrm{C}_{\mathrm{n}} \nabla \mathrm{F}\left(2 \mathrm{nC}_{3}\right.$ is both even vertex graceful and odd-edge graceful.

Definition 3.2: A fan graph or an extension-friendship graph $\mathbf{C}_{\mathbf{n}} \nabla$ $\mathbf{F}\left(\mathbf{3 n C}_{3}\right)$ is defined as the following connected graph such that every vertex of $C_{n}$ is merged with one copy of $3 C_{3}$. 


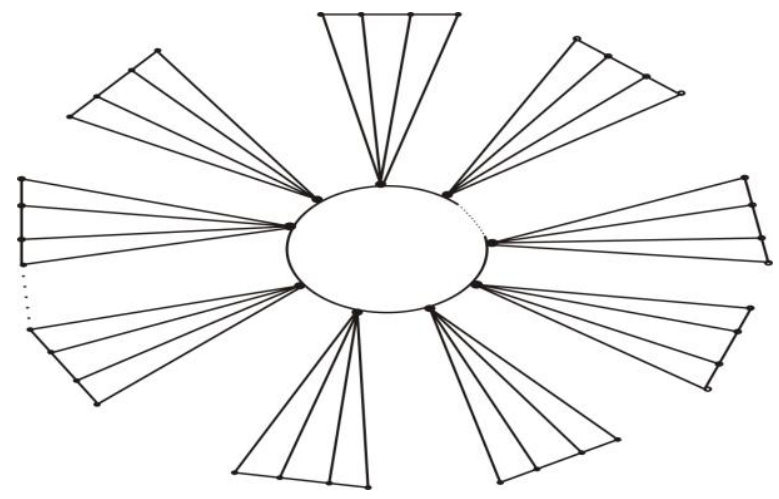

Theorem 3.2: The connected graph $\mathrm{C}_{\mathrm{n}} \nabla \mathrm{F}\left(3 \mathrm{nC}_{3}\right)$ is even vertex graceful.

Proof: The graph $\mathrm{C}_{\mathrm{n}} \nabla \mathrm{F}\left(3 \mathrm{nC}_{3}\right)$ is chosen with some arbitrary labeling of edges as in definition (1.6).

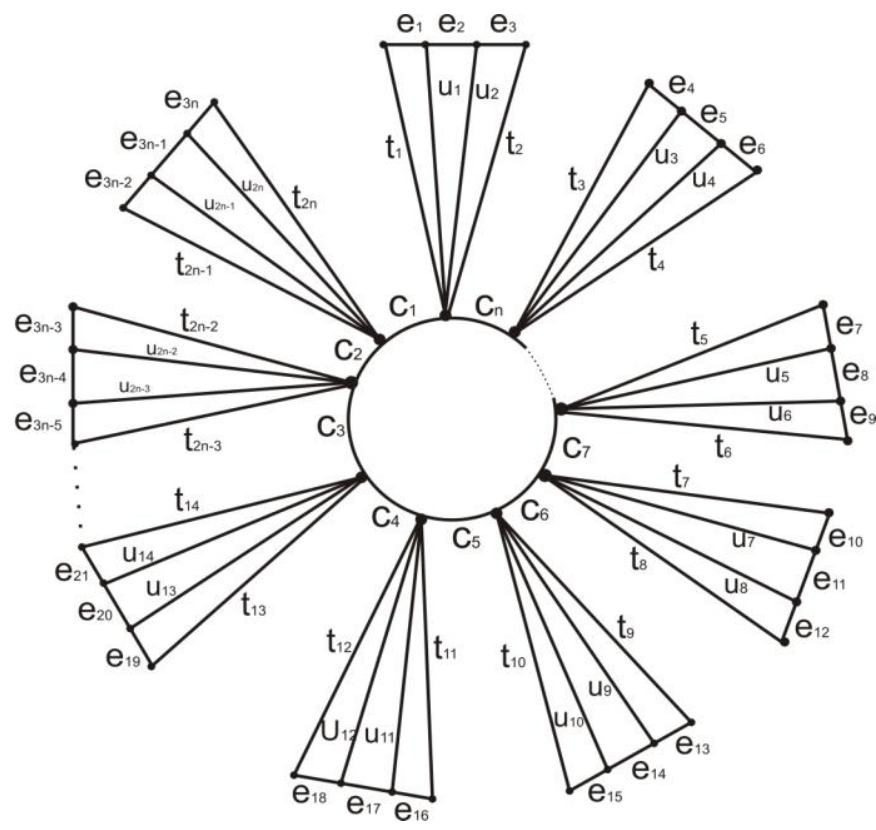

Define a map f: $\mathrm{E}\left[\mathrm{C}_{\mathrm{n}} \nabla \mathrm{F}\left(3 \mathrm{nC}_{3}\right)\right] \rightarrow\{0,1,2, \ldots, 2 \mathrm{q}\}$ by

$$
\begin{aligned}
& \mathrm{f}\left(\mathrm{e}_{\mathrm{i}}\right)=2 \mathrm{i}-1, \quad \mathrm{i}=1,2, \ldots, 3 \mathrm{n} \\
& \mathrm{f}\left(\mathrm{t}_{\mathrm{i}}\right)=\mathrm{f}\left(\mathrm{e}_{2 \mathrm{n}}\right)+2 \mathrm{i}, \quad \mathrm{i}=1,2, \ldots, 2 \mathrm{n} \\
& \mathrm{f}\left(\mathrm{u}_{1}\right)=(2 \mathrm{q}-4) \\
& \mathrm{f}\left(\mathrm{u}_{2}\right)=(2 \mathrm{q}-6) \\
& \mathrm{f}\left(\mathrm{u}_{\mathrm{i}}\right)=\mathrm{f}\left(\mathrm{u}_{1}\right)-4(\mathrm{i}-1) ; \quad \mathrm{i}=3,5,7, \ldots, 2 \mathrm{n}-1 \\
& \mathrm{f}\left(\mathrm{u}_{\mathrm{i}}\right)=\mathrm{f}\left(\mathrm{u}_{2}\right)-4(\mathrm{i}-2), \quad \mathrm{i}=4,6, \ldots, 2 \mathrm{n} \\
& \mathrm{f}\left(\mathrm{c}_{1}\right)=\mathrm{f}\left(\mathrm{u}_{2 \mathrm{n}}\right)-2 ; \mathrm{f}\left(\mathrm{c}_{2}\right)=\mathrm{f}\left(\mathrm{c}_{1}\right)-2 ; \\
& \mathrm{f}\left(\mathrm{c}_{\mathrm{i}}\right)=\mathrm{f}\left(\mathrm{c}_{1}\right)-3(\mathrm{i}-1) \text { where } \mathrm{i} \text { varies } 3,5,7, \ldots, \mathrm{n} \text { if } \mathrm{n} \text { is odd; } \mathrm{i} \text { varies } \\
& 3,5,7, \ldots, \mathrm{n}-1 \text { if } \mathrm{n} \text { is even. } \\
& \mathrm{f}\left(\mathrm{c}_{\mathrm{n}}\right)=\mathrm{f}\left(\mathrm{c}_{\mathrm{n}-1}\right)-4 \text { if } \mathrm{n} \text { is even; } \\
& \mathrm{f}\left(\mathrm{c}_{\mathrm{i}}\right)=\mathrm{f}\left(\mathrm{c}_{2}\right)-3(\mathrm{i}-2) \text { where } \mathrm{i} \text { varies } 2,4,6, \ldots, \mathrm{n} \text { if } \mathrm{n} \text { is even; i varies } \\
& 2,4,6, \ldots, n-1 \text { if } \mathrm{n} \text { is odd; } \\
& \mathrm{f}\left(\mathrm{c}_{\mathrm{n}}\right)=\mathrm{f}\left(\mathrm{c}_{\mathrm{n}-1}\right)-4 \text { if } \mathrm{n} \text { is odd }
\end{aligned}
$$

Then the induced map $\mathrm{f}^{+}(\mathrm{u})=\sum \mathrm{f}(\mathrm{uv}) \quad(\bmod 2 \mathrm{q})$ where the sum runs over all edges $u v$ through $v$. Now, $f$ and $\mathrm{f}^{+}$both satisfy even vertex graceful labeling Thus the connected graph $C_{n} \nabla F\left(3 C_{3}\right)$ is even vertex graceful
Definition 3.3: The graph $C(4, n)$ is a connected graph defined by merging $\mathrm{C}_{4}$ and $\mathrm{C}_{\mathrm{n}}$ as follows:

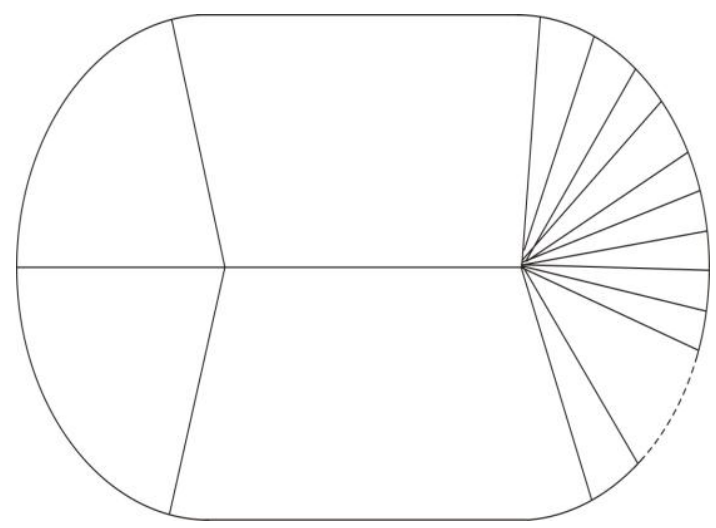

Theorem 3.3: The connected $\mathrm{C}(4, \mathrm{n})$ is even vertex graceful.

Proof: The graph $\mathrm{C}_{\mathrm{n}} \nabla \mathrm{F}\left(3 \mathrm{nC}_{3}\right)$ is chosen with some arbitrary labeling of edges as in definition (1.7).

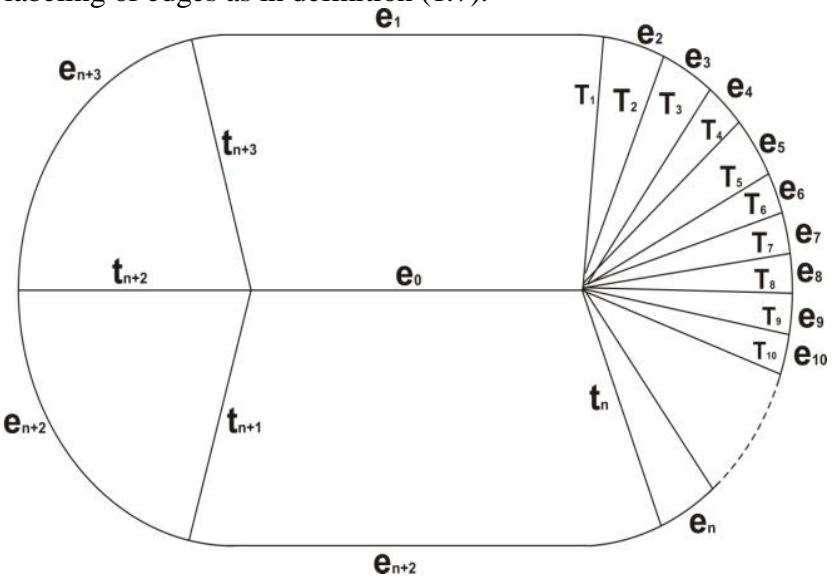

Define a map f: $\mathrm{E}[\mathrm{C}(4, \mathrm{n})] \rightarrow\{0,1,2, \ldots, 2 \mathrm{q}\}$ by

$$
\begin{array}{ll}
\mathrm{f}\left(\mathrm{e}_{\mathrm{i}}\right)=2 \mathrm{i}-1, & \mathrm{i}=1,2, \ldots,(\mathrm{n}+3) \\
\mathrm{f}\left(\mathrm{T}_{\mathrm{i}}\right)=2 \mathrm{q}-2(\mathrm{i}-1), & \mathrm{i}=1,2, \ldots,(\mathrm{n}+3) ; \\
\mathrm{f}\left(\mathrm{e}_{0}\right)=(\mathrm{q}-15)=(2 \mathrm{n}-8) &
\end{array}
$$

Then the induced map $\mathrm{f}^{+}(\mathrm{u})=\sum \mathrm{f}(\mathrm{uv}) \quad(\bmod 2 \mathrm{q})$ where the sum runs over all edges uv through $\mathrm{v}$. Now, $\mathrm{f}$ and $\mathrm{f}^{+}$both satisfy even vertex graceful labeling Thus the connected graph $\mathrm{C}(4, \mathrm{n})$ is even vertex graceful.

\section{CONCLUSION}

Even vertex graceful of friendship graphs $\mathrm{F}\left(\mathrm{nC}_{3}\right), \mathrm{F}\left(\mathrm{nC}_{5}\right)$, and $\mathrm{F}\left(2 \mathrm{nC}_{3}\right)$ are obtained in [7]. For further investigations. Path, circuit, star and wheel are all even vertex graceful. Also the connected graphs $\mathrm{C}_{\mathrm{n}} \nabla \mathrm{F}\left(2 \mathrm{nC}_{3}\right), \mathrm{C}_{\mathrm{n}} \nabla \mathrm{F}\left(3 \mathrm{nC}_{3}\right)$ and $\mathrm{C}(4, \mathrm{n})$ are all even vertex graceful..

\section{REFERENCES}

1. A. Solairaju and K.Chitra, Edge-odd graceful labeling of some graphs, Electronics Notes in Discrete Mathematics Volume 33, April 2009, pp. 15 
2. A. Solairaju and P.Muruganantham, even-edge gracefulness of ladder, The Global Journal of Applied Mathematics \& Mathematical Sciences (GJ-AMMS). Vol.1.No.2, (JulyDecember, 2008), pp.149-153.

3. A. Solairaju and P.Muruganantham, Even vertex gracefulness of path merging circuits, Indian Journal of Mathematics and Mathematical Sciences, Vol. 6, No.1, (June, 2010), pp.27 31.

4. A. Solairaju and P.Muruganantham, Even vertex gracefulness of even number of copies of $\mathrm{C}_{4}$, accepted for publication in Serials Publications, New Delhi, India.
5. A.Solairaju, and A.Sasikala, Gracefulness of a spanning tree of the graph of product of ${ }_{\mathrm{Pm}}$ and $\mathrm{Cn}$, The Global Journal of Pure and Applied Mathematics of Mathematical Sciences, Vol. 1, No-2 (July-Dec 2008): pp 133-136.

6. A.Solairaju, and C.Vimala, Gracefulness of a spanning tree of the graph of Cartesian product of $S_{m}$ and $S_{n}$, The Global Journal of Pure and Applied Mathematics of Mathematical Sciences, Vol. 1, No-2 (July-Dec 2008): pp117-120.

7. A. Solairaju and P.Muruganantham, Even vertex gracefulness of fan graph, International Journal of Computer Applications (0975-8887), Vol. 8, No.8, (October, 2010). 